\title{
Derrumbando Barreras en Contra de la Actividad Física ${ }^{1}$
}

Jennifer Hillan ${ }^{2}$

Mantenerse activo físicamente puede ayudarlo a mejorar su estado 2 ENAFS físico y mantenerse independiente. Esto también puede ayudarle a reducir el riesgo de padecer de enfermedades como la diabetes y a manejar las enfermedades que usted pueda ya estar sufriendo. Si usted no es una persona activa físicamente, ¿que lo detiene a comenzar? Siga leyendo para aprender como superar y derrumbar algunas de las barreras en contra de la actividad física.

\section{Barreras Comunes y Sus Soluciones}

No tengo el tiempo para realizar actividad física por 30 minutos cada día. Realice tanto como usted pueda. Toda actividad física cuenta. Empiece con 10 minutos al día e incremente gradualmente más tiempo. Usted no tiene que empezar realizando todos los 30 minutos de actividad física de una sola vez.

El vecindario donde vivo no está seguro de ir a caminar.

Encuentre una actividad física que usted pueda realizar bajo techo, por ejemplo como tomar una clase en un centro comunitario o ir a caminar en un centro comercial.

A mí no me gusta hacer ejercicio en grupo. Escoja una actividad que usted puede realizar por si mismo sin otras personas, como ir a caminar afuera o seguir un programa de aeróbicos en la televisión o en video.
Me aburre la actividad física.

Encuentre una actividad que a usted le gusta hacer. Pide que un amigo le acompañe. Varíe su rutina.

Al caminar me duelen las rodillas, y tengo problemas con mi equilibrio.

Trate de bailar sentado o practique natación.

Hace mucho calor afuera.

Camine dentro de un centro comercial o un supermercado o utilice un video de aeróbicos en casa.

No tengo la ropa apropiada.

Vista cualquier ropa que sea cómoda. Asegúrese que los zapatos le ajusten bien y que las medias no molesten o irriten su piel.

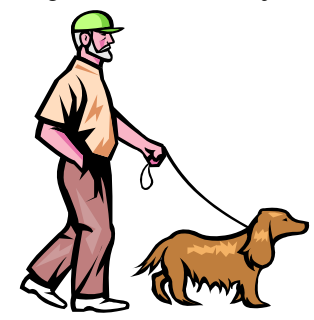

1. The English version of this Spanish document is Healthy Living: Barriers to Physical Activity (FCS8818). Adaptado de Overcoming Barriers, por la Asociación de la Diabetes. Este documento, FCS8818-Span, pertenece a una serie del Departamento de Ciencias de la Familia, Juventud y Comunidad, Servicio de Extensión Cooperativo de la Florida, Instituto de Alimentos y Ciencias Agrícolas, Universidad de la Florida. Fecha de publicación. diciembre 2006. Favor de visitar el EDIS Web site en el http://edis.ifas.ufl.edu

2. Jennifer Hillan, MSH, RD, LD/N,educadora/entrenadora, Departamento de Ciencias de la Familia, Juventud y Comunidad, Servicio de Extensión Cooperativo de la Florida, Instituto de Alimentos y Ciencias Agrícolas, Universidad de la Florida., Gainesville, Florida 32611. Traducción por Jessica R. A. Caicedo, Universidad de la Florida. 
Tengo miedo que mi enfermedad empeore. Habla con su proveedor de salud acerca de las actividades que son apropiados para usted.

No tengo suficiente dinero para ser miembro de un gimnasio o para comprar equipo atlético.

Lo único que usted necesita es un buen par de zapatos para caminar.

Tengo miedo que mis niveles de glucosa en la sangre disminuyan.

Si usted está tomando medicina que pueda causar que sus niveles de glucosa en la sangre disminuyan, hable con su proveedor de salud acerca de cómo realizar seguramente su actividad física. 